\title{
Long-Term Response to Daily
} Low-Dose Subcutaneous

\section{Interferon-a2b in a Patient with Pretreated Metastatic Uveal Melanoma in the Liver and Lung}

\author{
Pia Vihinen Seppo Pyrhönen \\ Department of Oncology and Radiotherapy, Turku University Hospital, \\ Turku, Finland
}

\section{Key Words}

Interferon-alpha (IFN-a) - Long-term response - Metastatic melanoma - Prognosis . Second-line therapy $\cdot$ Survival $\cdot$ Uveal melanoma

\begin{abstract}
Uveal melanoma is the most common primary intraocular malignancy in adults. Localized tumors are often curable by local therapy, but about $50 \%$ of patients develop a relapse with metastatic disease, particularly in the liver. Mortality rate after detected liver metastases remains high, while systemic therapies usually provide marginal benefit. Melanomas are hypervascular tumors, and agents with antiangiogenic activities have been studied as palliative treatment. Interferon-alpha-2b (IFN-a2b) has antiangiogenic activity when administered at low doses. We describe a patient who has received lowdose subcutaneous IFN-a2b ( $0.9 \mathrm{MIU}$, tid) continuously for years and gained stabilization of lung and liver metastases, which had previously progressed during earlier systemic therapies.
\end{abstract}

\section{Introduction}

Uveal melanomas of the choroidal and ciliary body are aggressive tumors causing the death of approximately $50 \%$ of patients. The survival rates at 5 and 15 years are $70 \%$ and $55 \%$, respectively $[1,2]$. Most of the metastases in uveal melanoma are detected in the liver $[3,4]$. Prolonged survival with metastatic uveal melanoma is relatively uncommon, usually median survival time is less than 12 months [5]. Cytokine-based therapies with interferon-alpha (IFN- $\alpha$ ) and interleukin-2, or chemotherapies using dacarbazine or other drugs commonly used to treat cutaneous melanoma, produce only rarely durable 


\begin{tabular}{|c|c|c|c|}
\hline $\begin{array}{l}\text { Cose Reports in } \\
\text { Binatily }\end{array}$ & $\begin{array}{l}\text { Case Rep Oncol 2008;1:5-10 } \\
\text { D0I: } 10.1159 / 000172797\end{array}$ & Published online: November 21, 2008 & $\begin{array}{l}\text { @ } 2008 \text { S. Karger AG, Basel } \\
\text { ISSN 1662-6575 } \\
\text { www.karger.com/cro }\end{array}$ \\
\hline
\end{tabular}

responses in uveal melanoma [6]. Dacarbazine and IFN- $\alpha$ have been used as adjuvant therapy in high-risk patients after primary therapy, but unfortunately these studies have not shown clinical benefit [ 7 and references therein]. We report a patient with metastatic uveal melanoma achieving long-term survival benefit and stable disease in response to single-agent low-dose subcutaneous (s.c.) interferon-alpha-2b (IFN- $\alpha 2 b)$ therapy.

\section{Case Report}

A 47-year-old woman presented in June 1991 with disturbed vision in her right eye, and a local choroidal melanoma was diagnosed. Tumor was treated with iodine 125 plaque brachytherapy (IBT) with a mean radiation dose of $87 \mathrm{~Gy}$ to the tumor apex. Treatment resulted in complete disease response and metastases were not detected until March 2004, when 3 separate, biopsy-proven liver metastases were detected. There were no other metastases detected on whole-body computed tomography (CT) scan or magnetic resonance imaging (MRI) of the liver. The patient presented with stage IVBa metastatic uveal melanoma [8]. Liver metastasis is shown on CT (fig. 1A). The patient received combined chemoimmunotherapy with BOLD (bleomycin $15 \mathrm{mg}$ on days 1 and 5 , vincristine $2 \mathrm{mg} / \mathrm{m}^{2}$ on days 1 and 4, lomustine $80 \mathrm{mg}$ on day 1 , and dacarbazine $200 \mathrm{mg} / \mathrm{m}^{2}$ on days $\left.1-5\right)$, and IFN- $22 \mathrm{~b}$ (3 $\mathrm{MIU} \times 1$ s.c. daily on day 8 onwards for 6 weeks, then $6 \mathrm{MIU} \times 3$ s.c. three times weekly) in a 28 -day cycle for 4 cycles. Unfortunately, in September 2004, liver MRI scan and whole-body CT scan showed progression in liver metastases (fig. 1B) and a new metastasis was detected in the right lung. Carboplatin-vinorelbine-interleukin-2 (IL-2) (carboplatin $450 \mathrm{mg} / \mathrm{m}^{2}$ on day 1, vinorelbine $30 \mathrm{mg} / \mathrm{m}^{2}$ on day 1 , and IL-2 9 MIU $\times 1$ s.c. on days $2-5$ and 9-12, in a 21-day cycle) combination was given as the second-line treatment for 4 cycles. Disease reevaluation in January 2005 showed stable disease and treatment was continued with single IL-2 $(9$ MIU $\times 1$ s.c. daily on days $1-4$ and $8-11$, in a 21-day cycle) for 4 more cycles. In June 2005, liver and whole-body CT scan showed marked progression of the disease and temozolomide $\left(150 \mathrm{mg} / \mathrm{m}^{2}\right.$ on days $1-5$, in a 28 -day cycle) was given for three cycles. In the next disease reevaluation in September 2005, the liver metastases had progressed and the lung metastasis was stable. Continuous IFN- $\alpha 2 \mathrm{~b}$ therapy with a dose of $0.9 \mathrm{MIU} \times 3$ s.c. daily was started as the fourth-line therapy for metastatic disease in October 2005. The patient has received this treatment now continuously for 35 months and is still on treatment. In the latest reevaluation in February 2008, the liver (fig. 1C) and lung metastases were stable when compared to the situation in October 2005, and new lesions have not appeared. The patient is in good condition and has survived with metastatic disease for $>54$ months (August 2008). A bar plot of the diameter of metastases over time and the various therapies shows stabilization of the previously progressing disease (ig. 2 ).

\section{Discussion}

Almost 50\% of the patients with uveal melanoma develop liver metastasis up to 15 years after diagnosis [3]. Studies comparing primary uveal melanomas and their corresponding metastases show that metastases are comprised of higher-grade malignant cell types, of which a part is nonclassifiable [8]. Metastatic uveal melanomas include diseases with low or rapid progression; typically, median survival time with metastases can vary from 2.2 to 12.5 months [5]. About $20 \%$ of patients survive 76 months, i.e. over 4 years, but the longest survivals are associated with surgery or targeted hepatic chemotherapy, which was not given to the patient reported here [5].

Estimated median doubling time of treated uveal melanoma metastases is 255 days and many uveal melanomas accelerate growth with progression [9]. Our patient originally presented with stage IVBa uveal metastatic melanoma, i.e. her predicted survival time was $\geq 12$ months [8]. In our case, disease stabilization was seen only during IL-2 therapy and the still ongoing IFN- $\alpha 2 b$ therapy (fig. 2). The overall disease responses to chemoimmunotherapies in metastatic uveal melanoma are usually poor [7 and references therein]. Only one partial remission was achieved among 48 patients with metastatic uveal melanoma, in a patient who had been treated with gemcitabine plus treosulfan versus treosulfan alone in a randomized phase II trial [12]. Previous reports of second- 
line treatment of metastatic uveal melanoma have shown that treatment is usually ineffective $[12,13]$. Terheyden et al. [13] found stable diseases as responses to the combination therapy of treosulfan/gemcitabine in patients who had received prior chemoimmunotherapy for metastatic uveal melanoma. However, maximal tumor diameter was only $40 \mathrm{~mm}$ in those patients whose disease stabilized [13].

The exact mechanism of action for IFN- $\alpha$ is not known, but IFN- $\alpha$ is thought to exert its effects through antiproliferative, apoptosis-inducing and antiangiogenic effects in addition to immunologic modulation. It is interesting that our patient responds to the low-dose IFN- $\alpha 2 b$ therapy, even though the same drug administered in a greater dose in combination with multichemotherapy did not show any effect. Some cell line studies have shown that different interferon subunits can regulate melanoma cell proliferation differently [13]. Particularly the a14 subunit, which is expressed in leukocyte-derived multisubtype IFN- $\alpha$ preparation (Multiferon), might exert different tumor responses also in vivo [13]. However, in the case of our patient, the same IFN- $\alpha 2 b$ preparation has been continuously used, suggesting that the mechanism of action of low-dose IFN- $\alpha 2 b$ differs from that of higher dose treatment.

The antiangiogenic properties of low-dose IFN- $\alpha 2$ have been discussed lately [14]. The antiangiogenic effect of IFN- $\alpha 2$ is based on frequent low-dose administration. Similarly, favorable adjuvant effects of IFN- $\alpha$ on recurrence-free survival of high-risk stage IIIa melanoma patients in long-term IFN- $\alpha$ therapy might be due to antiangiogenic effects [15]. These studies show that long duration of the therapy is more important than the amount of the IFN- $\alpha 2 b$ dose and this is also seen in our case. The role of angiogenesis and the vascular network in the development of metastases from uveal melanoma is particularly interesting because, due to the lack of lymphatic vessels, only hematogenous spread of uveal melanoma is possible [4]. It is possible that chemotherapies have affected some subpopulations of the metastatic tumor cells and now the survival of cells left behind depends on angiogenesis, whose inhibitory effect suppresses also the growth of the metastases.

We conclude that daily low-dose subcutaneous IFN- $\alpha 2 b$ might be useful in the treatment of metastatic choroidal melanoma after failure of combined chemoimmunotherapy and should be further studied among patients with metastatic uveal melanoma.

\section{Acknowledgments}

Our original studies have been supported by the Southwest Funds of the Finnish Cancer Research Foundation and Turku University Hospital EVO grant (projects 13040 and 13041). 


\begin{tabular}{c|l|l|l}
$\begin{array}{c}\text { Cose Reports in } \\
\text { Oncolady }\end{array}$ & $\begin{array}{l}\text { Case Rep Oncol 2008;1:5-10 } \\
\text { D0I: 10.1159/000172797 }\end{array}$ & Published online: November 21, 2008 & $\begin{array}{l}\text { O 2008 S. Karger AG, Basel } \\
\text { ISSN 1662-6575 } \\
\text { www.karger.com/cro }\end{array}$ \\
\hline
\end{tabular}

Fig. 1. A Liver CT scan in March 2004, before starting BOLD (bleomycin, vincristine, lomustine, dacarbazine) + interferon- $\alpha 2 b$ (IFN- $\alpha 2 b$ ) chemoimmunotherapy. Needle-biopsy proven liver metastasis is seen in the left lobe (inside the red box). Liver cysts are also present. B Liver CT scan in September 2004, before starting vinorelbine (VIN), carboplatin (CAR) + interleukin-2 (IL-2) therapy. The red box indicates the largest metastasis. C Liver CT scan in February 2008, after continuation of low-dose IFN$\mathrm{a} 2 \mathrm{~b}$ therapy for 29 months. The red box indicates the largest metastasis.
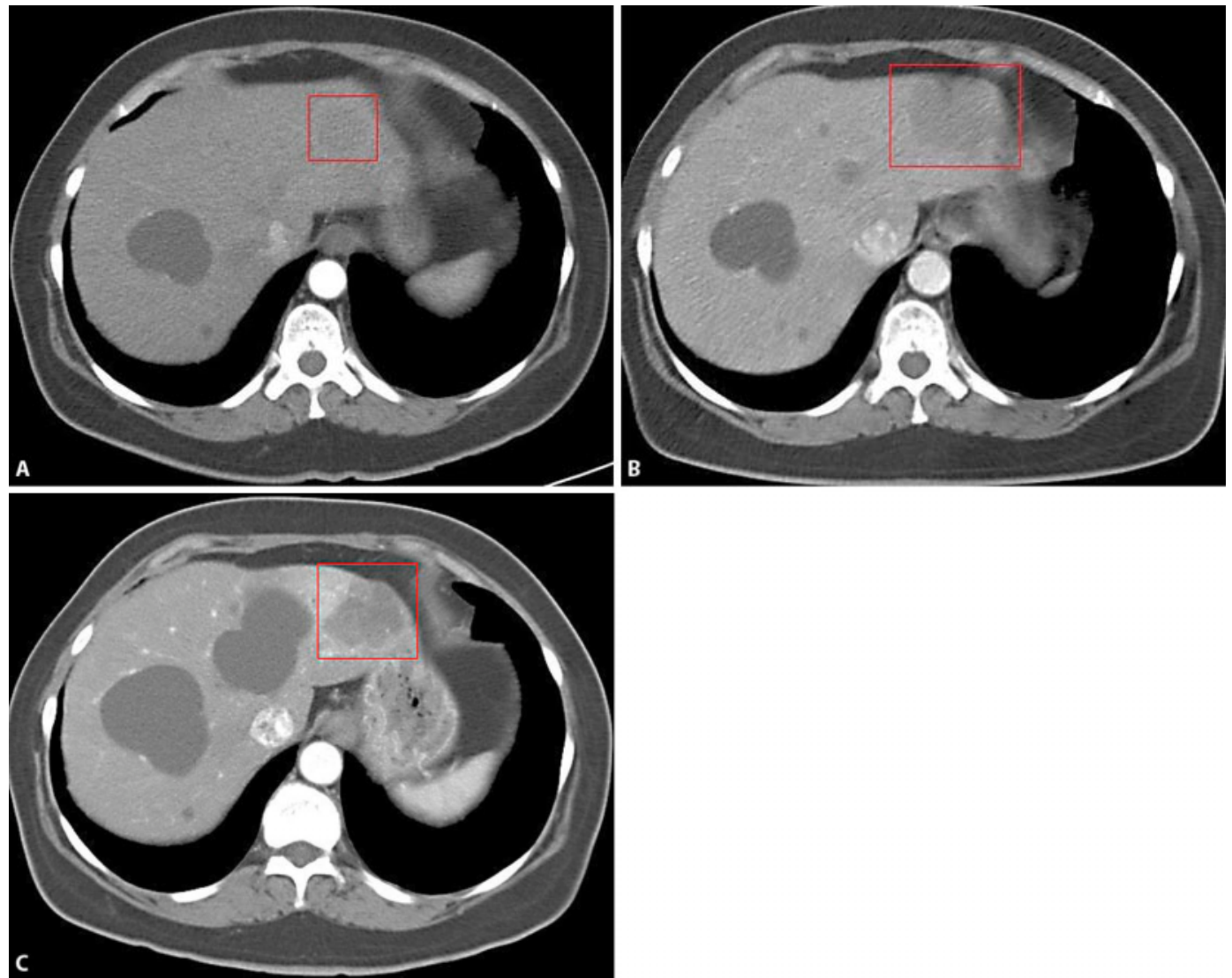
Fig. 2. Diameters of metastases over time. The largest diameters of three liver metastases and a lung metastasis are presented at different time points during the therapy. Progression of liver metastases was seen during the first 3 cytotoxic therapies, but administration of low-dose IFN- $\alpha 2 b$ led to long-term disease stabilization. BOLD = Bleomycin, vincristine, lomustine, dacarbazine; VIN-KAR-IL-2 = vinorelbine, carboplatin, interleukin-2; TEM = temozolomide; mo = months .

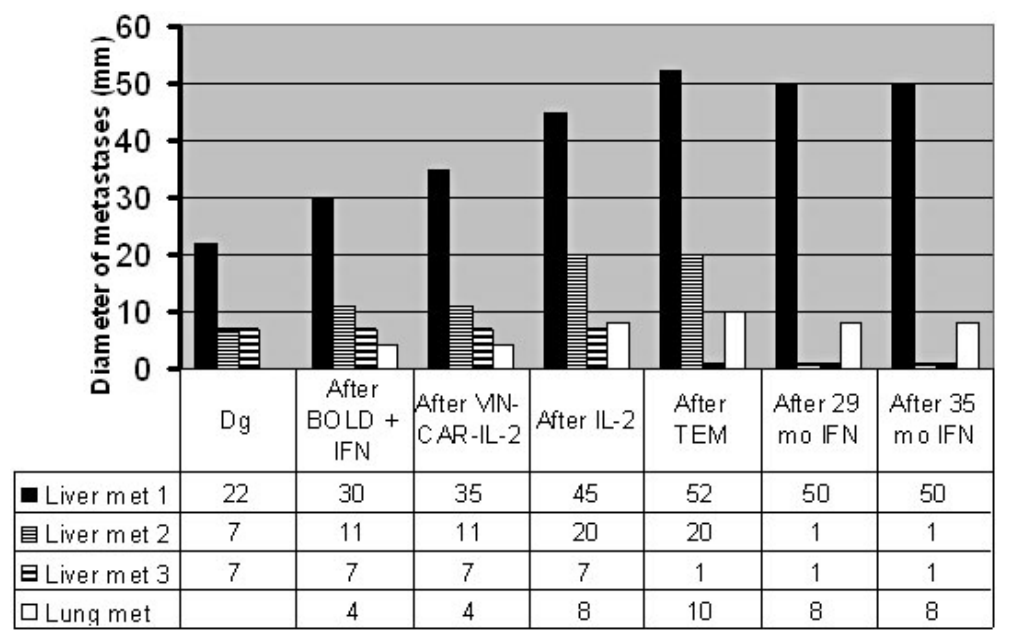




\begin{tabular}{|c|c|c|c|}
\hline $\begin{array}{c}\text { Cose Reports in } \\
\text { incion' }\end{array}$ & $\begin{array}{l}\text { Case Rep Oncol 2008;1:5-10 } \\
\text { D0I: } 10.1159 / 000172797\end{array}$ & Published online: November 21, 2008 & \begin{tabular}{|l} 
@ 2008 S. Karger AG, Basel \\
ISSN 1662-6575 \\
www.karger.com/cro
\end{tabular} \\
\hline
\end{tabular}

\section{References}

-1 Bergman L, Seregard S, Nilsson B, Lundell G, Ringborg U, Regnarsson-Olding B: Uveal melanoma survival in Sweden from 1960 to 1998. Invest Ophthalmol Vis Sci 2003;44:3282-3287.

-2 Kujala E, Mäkitie T, Kivelä T: Very long-term prognosis of patients with malignant uveal melanoma. Invest Ophthalmol Vis Sci 2003;44:4651-4659.

-3 Lorigan JG, Wallace S, Mavligit GM: The prevalence and location of metastases from ocular melanoma: imaging study in 110 patients. AJR Am J Roentgenol 1991;157:1279-1281.

-4 Bakalian S, Marshall JC, Logan P, Faingold D, Maloney S, Di Cesare S, Martins C, Fernandes BF, Burnier MN Jr: Molecular pathways mediating liver metastasis in patients with uveal melanoma. Clin Cancer Res 2008;14:951-956.

5 Rietschel P, Panageas KS, Hanlon C, Patel A, Abramson DH, Chapman PB: Variates of survival in metastatic uveal melanoma. J Clin Oncol 2005;23:80768080 .

-6 Singh AD, Borden EC: Metastatic uveal melanoma. Ophthalmol Clin North Am 2005; 18:143-150.

7 Triozzi PL, Eng C, Singh AD: Targeted therapy for uveal melanoma. Cancer Treat Rev 2008;34:247-258.

-8 Eskelin S, Pyrhönen S, Hahka-Kemppinen M, Tuomaala S, Kivelä T: A prognostic model and staging for metastatic uveal melanoma. Cancer 2003;97:465-475.

-9 Luyten GP, Mooy CM, Post J, Jensen OA, Luider TM, de Jong PT: Metastatic uveal melanoma. A morphologic and immunohistochemical analysis. Cancer 1996;78:1967-1971.

10 Eskelin S, Pyrhönen S, Summanen P, Hahka-Kemppinen M, Kivelä T: Tumor doubling times in metastatic malignant melanoma of the uvea. Ophthalmology 2000;107:1443-1449.

11 Schmittel A, Schmidt-Hieber M, Martus P, Bechrakis NE, Schuster R, Siehl JM, Foerster MH, Thiel E, Keilholz U: A randomized phase II trial of gemcitabine plus treosulfan versus treosulfan alone in patients with metastatic uveal melanoma. Ann Oncol 2006;17:1826-1829.

12 Schmidt-Hieber M, Schmittel A, Thiel E, Keilholz U: A phase II study of bendamustine chemotherapy as second-line treatment in metastatic uveal melanoma. Melanoma Res 2004;14:439-442.

13 Terheyden P, Bröcker EB, Becker JC: Clinical evaluation of in vitro chemosensitivity testing: the example of uveal melanoma. J Cancer Res Clin Oncol 2004;130:395-399.

14 Ruuth K, Berglund A, Munoz V, Lundgren E: Differential resistance of melanoma cells to treatment with recombinant IFN-alpha2b and leukocyte IFN. Anticancer Res 2007;27:2109-2114.

15 Shah GD, Chapman PB: Adjuvant therapy of melanoma. Cancer J 2007;13:217222. 